\title{
Comparing aboral versus oral pouch with preserved duodenal passage after total gastrectomy: does the position of the gastric substitute reservoir count?
}

\author{
Katalin Kalmár, Zsolt Káposztás, Gábor Varga, László Cseke, András Papp, and Örs Péter Horváth \\ Department of Surgery, University of Pécs, 13 Ifjuság str., 7624 Pécs, Hungary
}

\begin{abstract}
Background. Total gastrectomy results in a significant weight loss, different postgastrectomy symptoms, and a reduction in quality of life. Elaborate surgical reconstruction methods are evaluated to improve results. The present study compares two types of reconstructions-an aboral pouch with preserved duodenal passage and an oral pouch with preserved duodenal passage-differing only in the site of the pouch.

Methods. Twenty-eight patients entered the study. Primary outcome measures-body weight, body mass index, and quality of life, and secondary outcome measures-serum nutritional parameters, scintigraphic small-intestinal passage, and lipid and carbohydrate absorption were measured 6,12 , and 24 months after surgery.

Results. No significant differences were found in anthropometric parameters or in quality of life between the groups. Regarding the secondary outcome measures, albumin levels were higher in the oral pouch group, while protein and immunoglobulin-A levels were higher in the aboral pouch group. Conclusion. The site of the reservoir does not significantly influence the outcome after total gastrectomy and reconstruction with a preserved duodenal passage.
\end{abstract}

Key words Total gastrectomy - Gastric substitute · Pouch position · Nutrition · Quality of life

\section{Introduction}

The ideal reconstruction method after total gastrectomy replaces all lost functions of the stomach, i.e., it provides a large enough reservoir that can accommodate to the size of the meal, prevent reflux and dumping, ensure strong propulsion of equal-sized boluses of chyme enter-

Offprint requests to: K. Kalmár

Received: November 13, 2007 / Accepted: March 10, 2008 ing the duodenum, and respond properly to the changing levels of gastrointestinal hormones and neural information. The science of surgery is nowhere near reaching this ideal. With the gold standard Roux-en-Y reconstruction so far achieved, gastrectomized patients do not suffer from alkaline esophagitis. Different pouch construction methods and reconstructions of the duodenal passage are being trialled to improve functional results.

In our previous studies, a Roux-en-Y-based but distally reconstructed pouch-the aboral pouch-was compared to Roux-en-Y reconstruction, as well as being compared to reconstruction with an aboral pouch and duodenal passage preservation [1-4]. Absorption studies supported pouch construction; gastrointestinal hormone studies suggested the superiority of duodenal passage preservation [4]. In this study, the site of the pouch is examined; two different reconstruction types, the traditional oral pouch and the aboral pouch, are compared. Based on our gastrointestinal hormonal studies, we believe in the superiority of duodenal passage preservation, that is why both pouch reconstructions were performed with duodenal passage preservation.

\section{Patients and methods}

\section{Eligibility criteria and randomization}

All patients with a disease necessitating total gastrectomy were investigated for eligibility to enter the trial. Patients younger than 80 years, who had no historical data of previous bowel resection and in whom kidney and liver function tests had shown normal results, and in whom $\mathrm{R} 0$ resection could be performed, were considered eligible. During the operation, after evaluation of the feasibility of both reconstruction methods and clearance for technical resectability, randomization was performed via the envelope selection method. 
Table 1. Patients' characteristics

\begin{tabular}{|c|c|c|c|}
\hline & $\mathrm{AP}(n=14)$ & OP $(n=13)$ & $P$ \\
\hline Age (years) & 57.75 & 61.18 & 0.18 \\
\hline Sex: male/female & $5 / 9$ & $6 / 7$ & NS \\
\hline Histology: ACC/lymphoma & $13 / 1$ & $12 / 1$ & NS \\
\hline ACC stage: stage I/II/III & 4/6/4 & $5 / 5 / 3$ & NS \\
\hline Operative time $(\min )$ & $188 \pm 8$ & $189 \pm 15$ & NS \\
\hline \multicolumn{4}{|l|}{ Morbidity } \\
\hline Bleeding & 0 & 0 & NS \\
\hline Anastomotic insufficiency (esophageal) & 1 & 0 & \\
\hline Wound infection or abscess & 2 & 2 & \\
\hline Hospital stay & $14.2 \pm 3.2$ days & $15.0 \pm 3.4$ days & NS \\
\hline
\end{tabular}

ACC, adenocarcinoma; NS, not significantly different

\section{Patients}

Between 2002 and 2004, eligible patients during total gastrectomy were randomized either to undergo aboral pouch with preserved duodenal passage (AP) or oral pouch with preserved duodenal passage (OP) reconstruction. Fourteen patients entered the AP group, and 14 , the OP group. One patient from the OP group withdrew her consent before the basic 2-week postoperative measurements, so she was excluded from the study. Thus, 14 AP and 13 OP patients' data were analyzed. The patients' characteristics are summarized in Table 1 . No difference was shown between the two groups in age, sex, histology, or stage of the disease, neither in operation time nor the hospital stay. No operative mortality was observed in this patient population and there was no reconstruction-related morbidity.

\section{Operative methods}

Aboral pouch with preserved duodenal passage (AP). After total gastrectomy and D2 lymphadenectomy, a Roux limb is prepared from the first jejunal loop and pulled up, under the mesocolon, to the esophagus. The esophago-jejunostomy is constructed between the esophagus and the pulled-up Roux limb, end to side, with one-layer running suture or with staplers. The Roux limb is cut approximately $50 \mathrm{~cm}$ from the esophago-jejunostomy, but the mesentery is left intact. The oral end of the cut jejunum is sutured to the duodenal stump in an end-to-end fashion. The aboral part is pulled back under the mesocolon to participate in the creation of the aboral pouch. It is left temporarily open if staplers are used or is closed if a manual suture is decided upon. The aboral pouch is constructed under the mesocolon as an anisoperistaltic side-to-side anastomosis between the Roux limb and the Y limb, measuring $15 \mathrm{~cm}$ in length (Fig. 1) [5].

\section{Oral pouch with preserved duodenal passage (OP)}

After total gastrectomy and D2 lymphadenectomy, a Roux limb is prepared from the first jejunal loop and

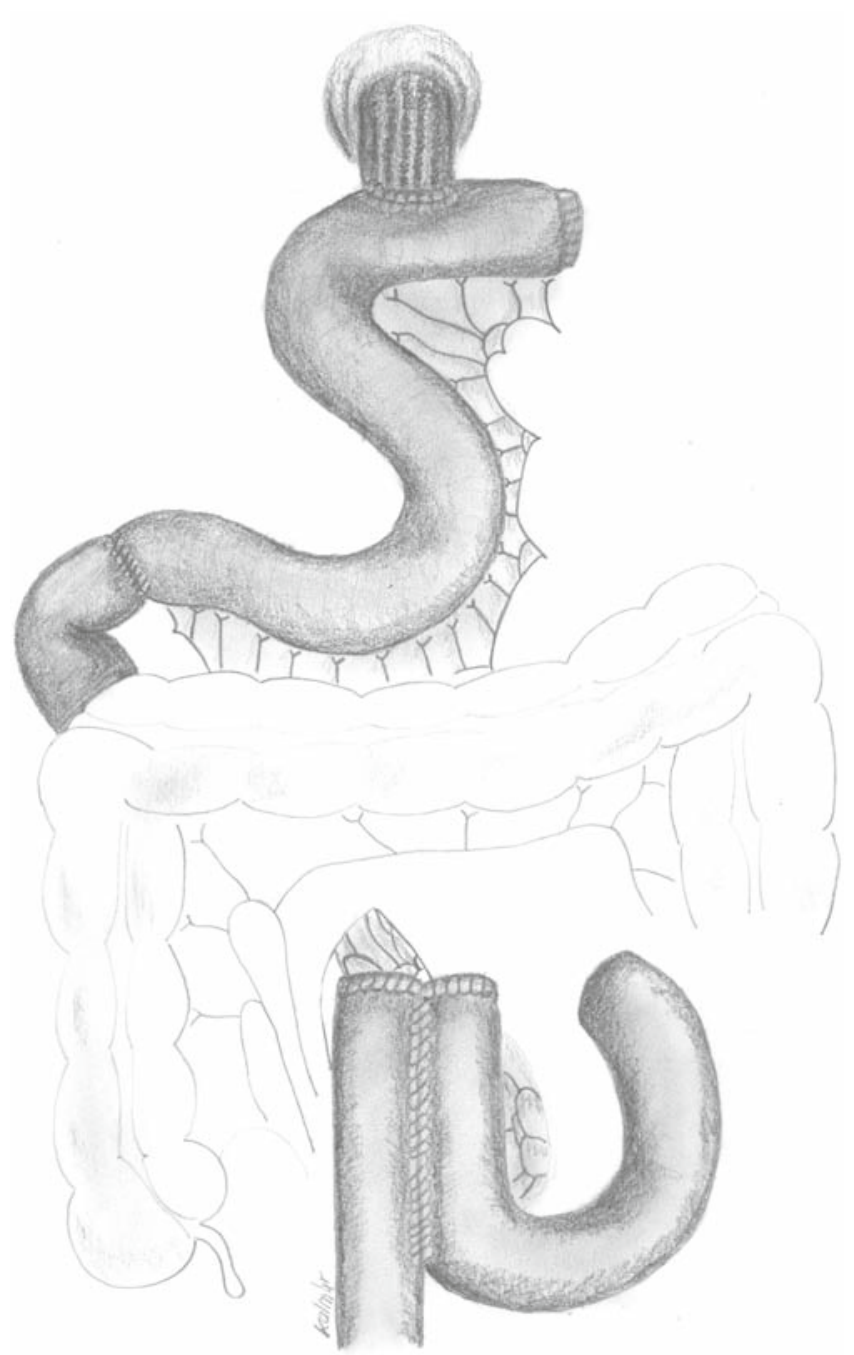

Fig. 1. Aboral pouch with preserved duodenal passage (AP) reconstruction

pulled up, under the mesocolon, to the esophagus. The pulled-up loop is folded over itself to create a J-pouch, measuring $15 \mathrm{~cm}$ in length. A side-to-side anastomosis is created manually or with staplers to form the pouch. The apex of the pouch is sutured to the esophagus end- 


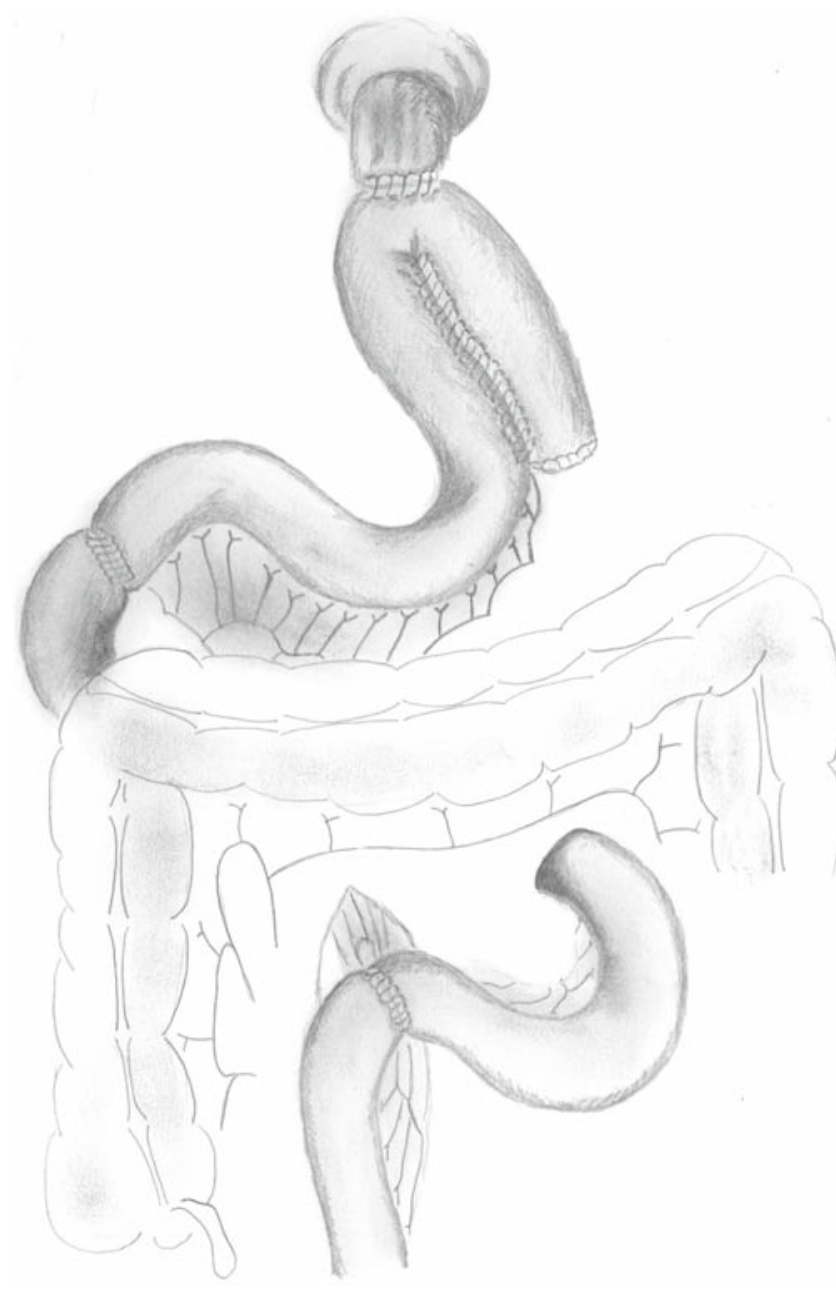

Fig. 2. Oral pouch with preserved duodenal passage (OP) reconstruction

to-side manually or with staplers. The Roux limb is cut approximately $50 \mathrm{~cm}$ from the esophago-jejunostomy, but the mesentery is left intact. The oral end of the cut jejunal limb is sutured to the duodenum in an end-toend manner, while the aboral end is pulled back under the mesocolon and is sutured to the free end of the $\mathrm{Y}$ limb, end to end, to reconstruct the full passage (Fig. 2).

\section{Methods of assessment}

Anthropometric measurements (body weight and height and body mass index [BMI] = weight in $\mathrm{kg}$ divided by height in $\mathrm{m}^{2}$ ) and laboratory measurements were done 2 weeks postoperatively as well as 6,12 , and 24 months after surgery. The following laboratoratory measurements were done: serum total protein $(\mathrm{g} / \mathrm{l})$, albumin $(\mathrm{g} / \mathrm{l})$, cholesterol $(\mathrm{mmol} / \mathrm{l})$, and triglyceride $(\mathrm{mmol} / \mathrm{l})$ levels; white blood count (G/l), absolute lymphocyte count $\left(/ \mathrm{mm}^{3}\right)$, and hemoglobin $(\mathrm{g} / \mathrm{l})$ and iron $(\mu \mathrm{mol} / \mathrm{l})$ levels; iron-binding capacity, measured as transferrin saturation (\%); and levels of immunoglobulin-A, immunoglobulin-G, immunoglobulin-M ( $\mathrm{g} / \mathrm{l})$, and transferrin $(\mathrm{g} / \mathrm{l})$. Onodera's prognostic nutritional index (OPNI) was calculated as follows: serum albumin $(\mathrm{g} / \mathrm{l}) \times$ absolute lymphocyte count $\left(/ \mathrm{mm}^{3}\right)$ [6]. Patients were submitted to more detailed follow-up examinations at 6,12 , and 24 months postoperatively, when motility and absorption studies were done and the quality of life was quantified by a gastrointestinal quality-of-life test.

Scintigraphic small-bowel passage examinations were carried out with an MB 9101 gammacamera, with the patient in the supine position, after the ingestion of $5 \mathrm{ml}$ of semisolid test meal mixed with $99 \mathrm{mTc}$-labeled diethylene-triamine-pentaacetate (DTPA). During the 1-hlong examination, images were obtained every minutes. A standard region of interest (ROI) was placed to the upper left quadrant of the abdomen in every patient. A time activity curve was reproduced from the scintigraphic activity, detected above this ROI. The emptying rate was calculated from the curve and was expressed in $\% / \mathrm{min}$, which is a velocity dimension [7].

Lipid and carbohydrate absorption was analyzed by means of the Lipiodol test and the D-xylose absorption test, respectively. These methods measure the urinary excretion of nonmetabolizable lipids and carbohydrates, respectively. The Lipiodol test needs a 24-h urine collection and the result is expressed in milligrams of iodine excreted (from Lipiodol, a lipid-soluble contrast material containing iodine) in the urine, in 24 hours. During the $\mathrm{D}$-xylose test, urine is collected for $5 \mathrm{~h}$ in five samples and the result is expressed as excreted milligrams of $\mathrm{D}$ xylose (a non-metabolizable hexose).

The quality of life was described by the Gastrointestinal Quality of Life Index (GIQLI) introduced by Eypasch [8] in 1995. This questionnaire consists of 36 questions concerning gastrointestinal complaints and physical and psychological wellbeing during the 2 weeks prior to the interview. The result of the test, the GIQLI, describes quality of life as a value of up to 144 points. Patients were requested to fill in the questionnaire by themselves, but a medical student was at hand in case patients had any problems with understanding the questions.

\section{Study design}

The primary endpoints or outcome measures of the trial were body weight, expressed better as change in the BMI (as a percentage of the early postoperative BMI), and quality of life, measured by the GIQLI (in points).

Secondary outcome measures were the measured laboratory parameters (serum total protein, albumin, 
triglyceride, cholesterol, hemoglobin, iron, transferrin saturation, transferrin, immunoglobulin-A, immunoglobulin-G, immunoglobulin-M, the OPNI, motility measures (scintigraphic small-bowel passage [SSBP]), and measures of absorption (lipid absorption, carbohydrate absorption).

\section{Statistics and ethics}

Values for results are expressed as means \pm SEM. Differences with a $P$ value $<0.05$ were considered significant. Statistical analysis was performed with SPSS 11.5 software. Statistical significance for parametric variables was analyzed by one-way analysis of variance (ANOVA). Nonparametric variables were tested by the $\chi^{2}$ test.

Study protocols were approved by the University of Pécs Ethics Committee. Written informed consent was obtained from each patient.

\section{Results}

Regarding the postoperative basic anthropometric and laboratory parameters, no significant difference was demonstrated between the AP and OP groups (Table 2).

\section{Anthropometric measurements}

As shown in Table 3 and Figs. 3 and 4, no significant differences were found between the AP and OP groups in body weight, BMI, or change in BMI (percentage of the postoperative BMI) 6, 12, and 24 months after surgery.

\section{Nutritional and immunologic laboratory measurements}

Most of the measured nutritional parameters followed a similar pattern in the two groups. No significant

Table 2. Basic anthropometric and laboratory parameters

\begin{tabular}{lrrc}
\hline & AP $(n=14)$ & OP $(n=13)$ & $P$ \\
\hline Body weight $(\mathrm{kg})$ & $61.33 \pm 1.72$ & $66.10 \pm 1.97$ & 0.08 \\
BMI $\left(\mathrm{kg} / \mathrm{m}^{2}\right)$ & $22.57 \pm 0.57$ & $24.19 \pm 0.62$ & 0.07 \\
Protein $(\mathrm{g} / \mathrm{l})$ & $65.09 \pm 2.85$ & $64.97 \pm 2.53$ & 0.97 \\
Albumin $(\mathrm{g} / \mathrm{l})$ & $33.05 \pm 1.58$ & $35.41 \pm 1.76$ & 0.32 \\
Triglyceride $(\mathrm{mmol} / \mathrm{l})$ & $1.75 \pm 0.18$ & $1.99 \pm 0.22$ & 0.40 \\
Cholesterol $(\mathrm{mmol} / \mathrm{l})$ & $4.93 \pm 0.35$ & $4.78 \pm 0.25$ & 0.74 \\
Hemoglobin $(\mathrm{g} / \mathrm{l})$ & $113.24 \pm 5.57$ & $114.39 \pm 3.76$ & 0.87 \\
Iron $(\mu \mathrm{mol} / \mathrm{l})$ & $8.35 \pm 2.05$ & $7.77 \pm 1.36$ & 0.82 \\
Transferrin sat $(\%)$ & $9.70 \pm 3.33$ & $14.57 \pm 2.27$ & 0.25 \\
Transferrin $(\mathrm{g} / \mathrm{l})$ & $2.30 \pm 0.19$ & $2.03 \pm 0.20$ & 0.35 \\
IgA $(\mathrm{g} / \mathrm{l})$ & $2.61 \pm 0.46$ & $3.00 \pm 0.38$ & 0.54 \\
IgG $(\mathrm{g} / \mathrm{l})$ & $8.37 \pm 0.97$ & $9.02 \pm 0.78$ & 0.62 \\
IgM $(\mathrm{g} / \mathrm{l})$ & $1.18 \pm 0.24$ & $1.55 \pm 0.19$ & 0.26 \\
OPNI & $43.84 \pm 1.78$ & $45.83 \pm 3.69$ & 0.62 \\
\hline
\end{tabular}

differences were found regarding serum triglyceride, cholesterol, hemoglobin, iron, transferrin, and OPNI between the two groups (Table 3). However, serum albumin was significantly higher in patients with an oral pouch at 6, 12, and 24 months' follow-up (Table 3, Fig. $5)$. On the other hand, serum protein was significantly higher in the AP group at 6 months (Fig. 6) and serum immunoglobulin-A was also significantly higher in the AP patients, at 24 months (Fig. 7).

\section{Scintigraphic small-bowel passage study (SSBP)}

No significant difference between the two groups was demonstrated regarding the emptying rate of the technetium-labeled test meal during small-bowel passage scintigraphy.

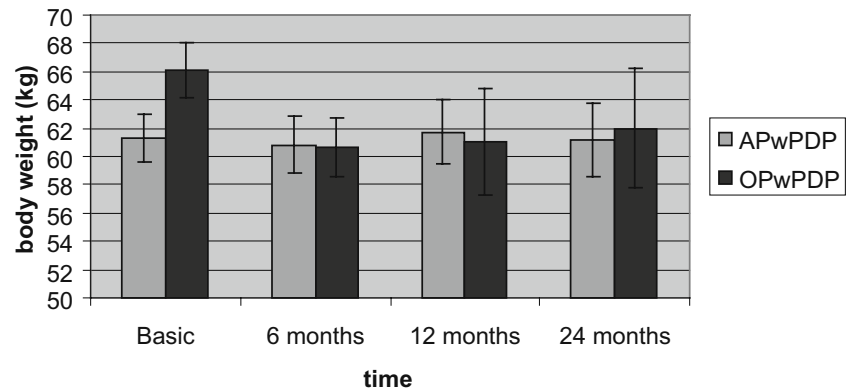

Fig. 3. Results of body weight measurements. $A P w P D P$, Aboral pouch with preserved duodenal passage; $O P$ w $P D P$, oral pouch with preserved duodenal passage (OP)

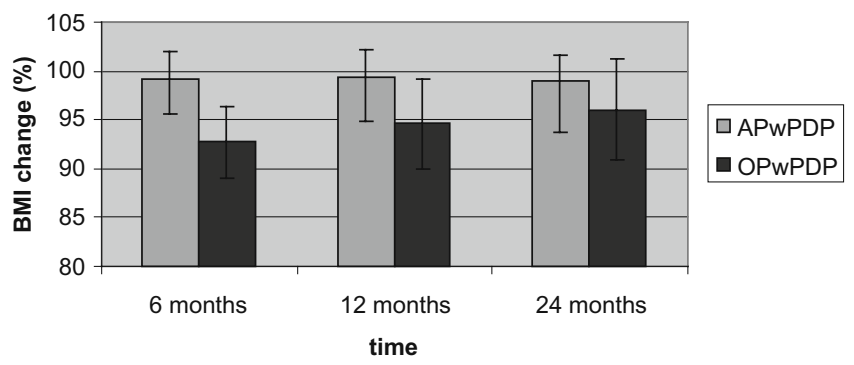

Fig. 4. Body mass index $(B M I)$ changes

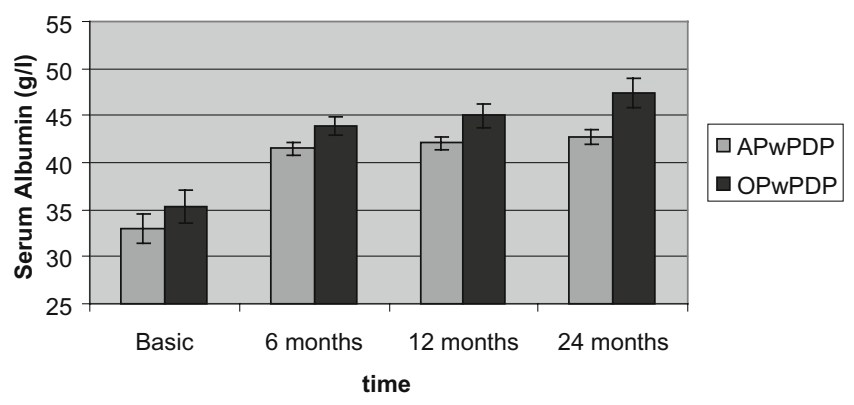

Fig. 5. Results of serum albumin measurements 
Table 3. Results of nutritional, laboratory, motility, absorption, and quality-of-life measurements

\begin{tabular}{|c|c|c|c|}
\hline $\begin{array}{l}\text { Parameter } \\
\text { and number of months }\end{array}$ & $\mathrm{AP}(n=14)$ & $\mathrm{OP}(n=13)$ & $P$ \\
\hline \multicolumn{4}{|l|}{ Body weight (kg) } \\
\hline 6 & $60.81 \pm 2.02$ & $60.60 \pm 2.09$ & 0.95 \\
\hline 12 & $61.71 \pm 2.27$ & $61.00 \pm 3.76$ & 0.86 \\
\hline 24 & $61.18 \pm 2.57$ & $62.00 \pm 4.22$ & 0.86 \\
\hline \multicolumn{4}{|l|}{$\mathrm{BMI}\left(\mathrm{kg} / \mathrm{m}^{2}\right)$} \\
\hline 6 & $22.31 \pm 0.55$ & $22.22 \pm 0.73$ & 0.92 \\
\hline 12 & $22.68 \pm 0.71$ & $22.68 \pm 0.97$ & 0.99 \\
\hline 24 & $23.13 \pm 0.97$ & $22.66 \pm 1.17$ & 0.76 \\
\hline \multicolumn{4}{|l|}{ BMI (\%) } \\
\hline 6 & $99.14 \pm 2.76$ & $92.69 \pm 3.63$ & 0.16 \\
\hline 12 & $99.43 \pm 2.74$ & $94.61 \pm 4.65$ & 0.38 \\
\hline 24 & $98.91 \pm 2.72$ & $96.05 \pm 5.11$ & 0.64 \\
\hline \multicolumn{4}{|l|}{ Protein $(g / l)$} \\
\hline 6 & $73.22 \pm 1.34$ & $69.81 \pm 0.74$ & $0.05^{*}$ \\
\hline 12 & $72.92 \pm 1.29$ & $72.18 \pm 1.66$ & 0.72 \\
\hline 24 & $74.63 \pm 0.75$ & $74.70 \pm 1.73$ & 0.61 \\
\hline \multicolumn{4}{|l|}{ Albumin (g/l) } \\
\hline 6 & $41.50 \pm 0.71$ & $43.89 \pm 1.01$ & $0.05^{*}$ \\
\hline 12 & $42.10 \pm 0.71$ & $45.04 \pm 1.26$ & $0.04 *$ \\
\hline 24 & $42.76 \pm 0.72$ & $47.37 \pm 1.55$ & $0.007 *$ \\
\hline \multicolumn{4}{|l|}{ Triglyceride (mmol/l) } \\
\hline 6 & $1.32 \pm 0.15$ & $1.43 \pm 0.16$ & 0.61 \\
\hline 12 & $1.32 \pm 0.12$ & $2.00 \pm 0.65$ & 0.23 \\
\hline 24 & $1.38 \pm 0.22$ & $1.30 \pm 0.16$ & 0.79 \\
\hline \multicolumn{4}{|l|}{ Cholesterol (mmol/l) } \\
\hline 6 & $5.14 \pm 0.24$ & $5.09 \pm 0.22$ & 0.89 \\
\hline 12 & $5.46 \pm 0.28$ & $4.71 \pm 0.36$ & 0.11 \\
\hline 24 & $5.69 \pm 0.26$ & $5.19 \pm 0.30$ & 0.24 \\
\hline \multicolumn{4}{|l|}{ Hemoglobin $(\mathrm{g} / \mathrm{l})$} \\
\hline 6 & $126.57 \pm 4.02$ & $125.18 \pm 3.81$ & 0.80 \\
\hline 12 & $128.00 \pm 4.11$ & $130.96 \pm 4.49$ & 0.63 \\
\hline 24 & $132.92 \pm 3.00$ & $132.22 \pm 3.45$ & 0.88 \\
\hline \multicolumn{4}{|l|}{ Iron $(\mu \mathrm{mol} / \mathrm{l})$} \\
\hline 6 & $16.74 \pm 2.11$ & $18.18 \pm 1.48$ & 0.60 \\
\hline 12 & $21.99 \pm 2.42$ & $18.29 \pm 1.47$ & 0.26 \\
\hline 24 & $21.39 \pm 1.64$ & $22.71 \pm 1.38$ & 0.58 \\
\hline \multicolumn{4}{|l|}{ Transferrin sat (\%) } \\
\hline 6 & $22.87 \pm 7.16$ & $30.25 \pm 3.37$ & 0.31 \\
\hline 12 & $29.87 \pm 4.35$ & $30.52 \pm 3.64$ & 0.91 \\
\hline 24 & $29.00 \pm 2.59$ & $33.45 \pm 3.73$ & 0.32 \\
\hline \multicolumn{4}{|l|}{ Transferrin (g/l) } \\
\hline 6 & $2.81 \pm 0.19$ & $2.66 \pm 0.20$ & 0.60 \\
\hline 12 & $3.00 \pm 0.19$ & $2.72 \pm 0.20$ & 0.34 \\
\hline 24 & $3.20 \pm 0.15$ & $2.95 \pm 0.15$ & 0.29 \\
\hline \multicolumn{4}{|l|}{$\operatorname{IgA}(g / l)$} \\
\hline 6 & $3.29 \pm 0.52$ & $2.55 \pm 0.33$ & 0.29 \\
\hline 12 & $3.08 \pm 0.52$ & $2.53 \pm 0.35$ & 0.44 \\
\hline 24 & $3.75 \pm 0.43$ & $2.20 \pm 0.28$ & $0.01 *$ \\
\hline \multicolumn{4}{|l|}{$\operatorname{IgG}(\mathrm{g} / \mathrm{l})$} \\
\hline 6 & $12.05 \pm 0.99$ & $10.40 \pm 0.41$ & 0.18 \\
\hline 12 & $10.81 \pm 0.87$ & $10.18 \pm 0.56$ & 0.60 \\
\hline 24 & $11.90 \pm 0.80$ & $10.71 \pm 0.47$ & 0.28 \\
\hline \multicolumn{4}{|l|}{$\operatorname{IgM}(\mathrm{g} / \mathrm{l})$} \\
\hline 6 & $1.03 \pm 0.12$ & $0.98 \pm 0.15$ & 0.82 \\
\hline 12 & $1.35 \pm 0.24$ & $1.03 \pm 0.18$ & 0.35 \\
\hline 24 & $1.55 \pm 0.24$ & $1.23 \pm 0.19$ & 0.37 \\
\hline \multicolumn{4}{|l|}{ OPNI } \\
\hline 6 & $53.27 \pm 1.39$ & $55.78 \pm 2.93$ & 0.41 \\
\hline 12 & $54.79 \pm 1.54$ & $55.67 \pm 1.86$ & 0.71 \\
\hline 24 & $54.90 \pm 1.42$ & $56.41 \pm 1.66$ & 0.50 \\
\hline
\end{tabular}


Table 3. Continued

\begin{tabular}{lrrr}
\hline $\begin{array}{l}\text { Parameter } \\
\text { and number of months }\end{array}$ & AP $(n=14)$ & OP $(n=13)$ & $P$ \\
\hline GIQLI & $97.33 \pm 4.29$ & $91.11 \pm 8.32$ & 0.47 \\
$\quad 6$ & $106.00 \pm 4.04$ & $95.40 \pm 6.81$ & 0.16 \\
12 & $101.45 \pm 5.73$ & $101.78 \pm 6.45$ & 0.97 \\
24 & $0.35 \pm 0.08$ & $0.33 \pm 0.09$ & 0.88 \\
SSBP $(\% / \mathrm{min})$ & $0.50 \pm 0.10$ & $0.28 \pm 0.11$ & 0.16 \\
6 & $0.58 \pm 0.12$ & $0.39 \pm 0.11$ & 0.31 \\
12 & & & \\
24 & $2.66 \pm 0.16$ & $3.23 \pm 0.26$ & 0.07 \\
Lipiodol (mg) & $2.87 \pm 0.19$ & $3.45 \pm 0.45$ & 0.17 \\
6 & $3.19 \pm 0.38$ & $3.75 \pm 0.17$ & 0.35 \\
12 & $1072 \pm 205$ & $639 \pm 112$ & 0.11 \\
24 & $1204 \pm 185$ & $905 \pm 107$ & 0.21 \\
Xylose (mg) & $1257 \pm 154$ & $864 \pm 111$ & 0.06 \\
6 & & & \\
12 & $4.88 \pm 0.23$ & $5.64 \pm 0.15$ & $0.02 *$ \\
24 & $5.13 \pm 0.27$ & $5.38 \pm 0.26$ & 0.57 \\
No of meals & $5.25 \pm 0.25$ & $4.86 \pm 0.34$ & 0.36 \\
6 & & & \\
12 & & & \\
24 & & & \\
\hline
\end{tabular}

* Significant differences were found in serum protein level at 6 months; serum albumin at 6,12 , and 24 months; immunoglobulin-A level at 24 months; and in the number of meals taken per day at 6 months. $P$ values for ANOVA are represented. Post-hoc test results revealing the source of difference are detailed in the text

Transferrin sat $\%$, transferrin saturation as percentage; no. of meals, number of meals per day

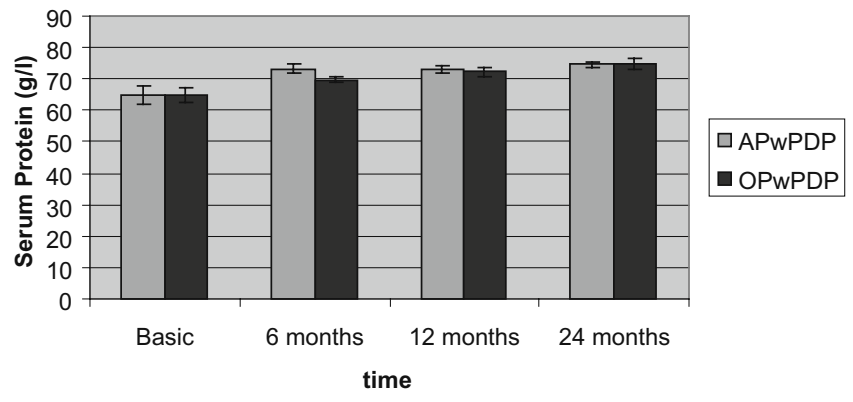

Fig. 6. Results of serum protein measurements

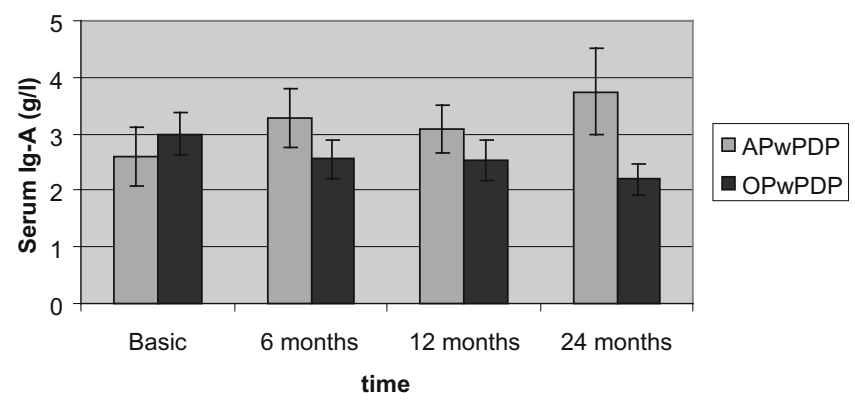

Fig. 7. Results of serum immunoglobulin-A measurements

\section{Lipid and carbohydrate absorption tests}

There was a tendency toward better lipid absorptiontested by the Lipiodol study-in the OP patients at 6 months, but the tendency had disappeared by 12 months

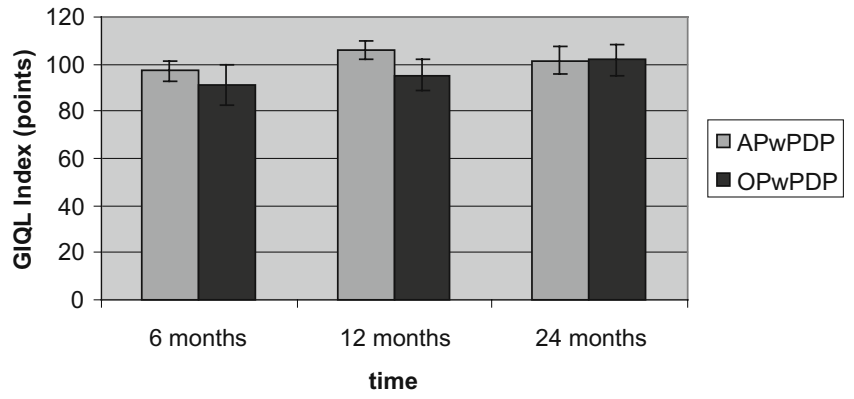

Fig. 8. Results of quality-of-life measurements. GIQL, Gastrointestinal Quality of Life

(Table 3). And there was a tendency towards better carbohydrate absorption-measured by the Xylose test in the AP patients; this tendency appeared after 6 months and the difference almost reached significance by 24 months (Table 3 ). Nevertheless no significant difference was demonstrated between the AP and OP groups in the results of the absorption studies.

\section{Quality of life}

The quality of life-tested by Eyspach's [8] GIQLIwas similar in the two groups, slightly increasing with time; but no difference was observed between the groups (Table 3, Fig. 8). 


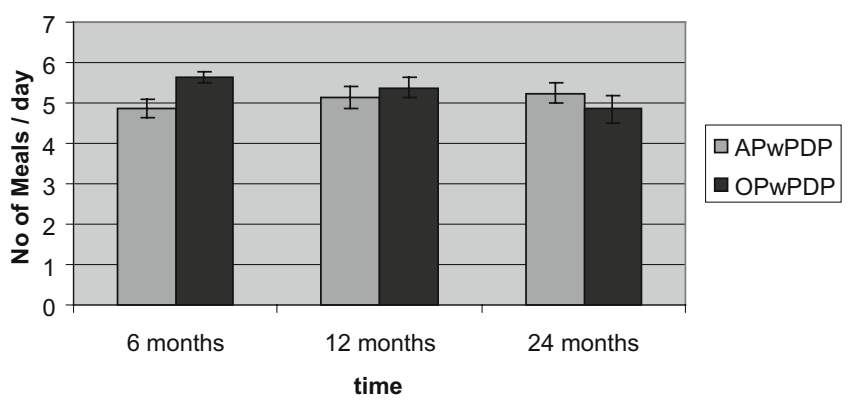

Fig. 9. Number of meals taken per day

The number of meals taken per day differed significantly at 6 months in favor of the AP group, but the difference disappeared with time (Table 3, Fig. 9).

\section{Discussion}

Randomized studies published in this field mainly question the importance of reservoir construction [1, 9-22]; fewer trials research the importance of duodenal passage preservation [11, 14, 23-26]. Two expert reviews have been published, each trying to draw evidence-based conclusions by means of a metaanalysis of all available randomized trials $[27,28]$. However both found that the lack of homogeneity in data regarding the type of reservoir, the method of performing any single type of reconstruction, and the differences in the parameters examined and in the length of follow-up precluded any formal statistical metaanalysis. Nevertheless they drew the conclusion that these more complicated reconstructions were feasible without any disadvantage compared to the standard Roux-en-Y reconstruction; reservoir construction was supported by substantial evidence, while duodenal passage preservation was supported by less evidence.

In the present trial, the importance of the position of the replacement reservoir was studied. One group of patients underwent a reconstruction with oral pouch formation and duodenal passage preservation (OP group), the other group received reconstruction with aboral pouch formation and duodenal passage preservation (AP group). The oral pouch we used is the HuntLawrence-Rodino pouch, which was first described separately by Hunt [29] and Rodino [30] in 1952, with a slight modification being described in 1962 by Lawrence [31]. It is performed at the site of the removed stomach, directly below the esophago-jejunal anastomosis (Fig. 2). Aboral pouch construction was used by our group in 2000 [1, 32], after a Medline search, as far as we were aware-as a new type of reconstruction. Later it was realized that Paulino [33] had described a similar method, but with a shorter pouch and end-to- end esophago-jejunostomy. Nadrowski et al. [34], in 2003, described the same method, suggesting it as an easy modification of the standard Roux-en-Y with an additional reservoir function.

Whoever constructed it first, the aboral pouch has not been compared to the well-established oral gastric reservoir in a randomized study to date. We have reported here a randomized comparison of the aboral pouch with preserved duodenal passage to the oral pouch with preserved duodenal passage after total gastrectomy.

Pouches provide a food reservoir, enabling patients to take larger meal volumes than would be possible without reservoir construction after total gastrectomy. Theoretically, to place the replacement reservoir aborally $-40-50 \mathrm{~cm}$ from the esophageal anastomosis, at the $\mathrm{Y}$ branching of the reconstruction instead of directly below the esophagus-may have some advantages. The reservoir, being a double-lumened smallbowel segment with longitudinally cut circular muscles, is a brake in the propelled motion of food. To slow down the passage of food like this has not much purpose orally right below the esophagus; however, aborally it gives a possibility for the food and bile, as well as pancreatic juice, to mix. Stagnation of food in the oral pouch is not only unhelpful, but may be harmful if it leads to reflux from the pouch to the esophagus. Pouchesophageal reflux is a described phenomenon that has even motivated some authors to apply an antireflux wrap for oral pouches [35].

Our previous study comparing the aboral pouch to simple Roux-en-Y reconstruction supported better lipid digestion and absorption in patients with pouch construction [1,2]. These better results may also have originated from the stagnation of food provided by the aboral pouch at a point where the food can mix with the digestive juices. However, in the present study, no such difference was found in favor of aboral pouch construction, probably because duodenal passage preservation provides more important advantages from this aspect, masking the smaller difference arising from the site of the pouch.

There are some technical aspects supporting aboral pouch construction over oral pouch construction. The construction of an aboral pouch is easier; it needs only one or two staplers, while the construction of an oral pouch is more complicated and more critical because of the esophageal anastomosis to the pouch. Another technical point is that, for an oral pouch, a longer Roux limb needs to be prepared, to keep the 40- to 50-cm distance between the esophagus and the bile entry after creating the pouch from a duplicate of jejunum. For this, during preparation of the Roux limb, it is not enough to ligate one direct jejunal artery; often it is necessary to ligate two jejunal arteries, which puts the end of the Roux limb at a higher risk of ischemia. 
Some authors have created both types of pouches in one reconstruction. In the study of Gioffre'Florio et al. [19], the oral pouch was compared with a double-pouch method combining oral pouch construction with an inframesocolic aboral pouch construction, similar to our aboral pouch, except that in our method, the anastomosis is performed in an anisoperistaltic fashion, while in the lower pouch of Gioffre'Florio's [19] double-pouch method, the anastomosis is performed in an isoperistaltic fashion. They found better weight gain and quality of life and higher serum albumin and total protein in patients with the double pouch compared to findings in patients with the J-pouch, which also supports the superiority of the J-pouch.

The present study, comparing aboral and oral pouches, both with preserved duodenal passage, did not find any significant differences between the two groups regarding the primary endpoints, i.e., body weight and quality of life were not affected by the position of the pouch during reconstruction after total gastrectomy.

Regarding the secondary endpoints, some differences were revealed. The serum level of albumin was higher in the OP patients at 6,12 , and 24 months postoperatively. It is difficult to find a clear-cut explanation for this, especially in the light of the finding that serum protein levels were higher in the AP group (although only at 6 months postoperatively), while serum immunoglobulin-A levels were also higher in the AP group (but only at 24 months postoperatively). Thus these higher albumin levels do not reflect a better protein metabolism in the OP patients in general. Serum protein and albumin-as some of the most well-known nutritional laboratory measures-have been examined in some studies [11, 19,21], but were found to be affected in only few [11, 19]. Nakane et al. [11] found a significantly higher protein level in patients with an oral pouch with duodenal exclusion reconstruction, compared to Roux-en-Y, 12 and 24 but not 6 months after surgery. They measured serum albumin too, and found no difference in albumin levels comparing oral pouch with duodenal exclusion, oral pouch with duodenal preservation, and Roux-en-Y. In another trial, when they compared an oral pouch with duodenal passage preservation and an oral pouch without duodenal passage preservation, no differences were found, even in serum protein levels [26]. In Gioffre Florio's study [19], as mentioned above, a double pouch (oral + aboral) resulted in higher protein and albumin levels than an oral pouch only.

In the present study, a significant difference was found in favor of the AP group in the number of meals taken per day, but this was found only at 6 months; then it equalized and even became better in the OP patients at 24 months, though not significantly so. The rest of the measured parameters-serum cholesterol, triglyceride, hemoglobin, iron, transferrin saturation, transferrin,
OPNI, SSBP and the lipid and carbohydrate absorption tests, did not differ significantly between the OP and AP patients.

In summary, the site of the reservoir, when added to a duodenal passage-preserving reconstruction, did not result in any major difference in the examined parameters in the first 2 years after surgery. The simplicity of the construction supports an aboral pouch over an oral pouch to improve the results of reconstruction after total gastrectomy.

Acknowledgments Statistical analysis was performed under the supervision of László Pótó at the Institute of Bioanalytics, University of Pécs. The trial was financed from a Hungarian Governmental Research Grant (OTKA T 42726).

\section{References}

1. Kalmár K, Cseke L, Zámbó K, Horváth ÖP. Comparison of quality of life and nutritional parameters after total gastrectomy and a new type of pouch construction with simple Roux-en-Y reconstruction. Dig Dis Sci 2001;46:1791-6.

2. Horváth ÖP, Kalmár K, Cseke L, Pótó L, Zámbó K. Nutritional and life-quality consequences of aboral pouch construction after total gastrectomy: a randomised, controlled study. Eur J Surg Oncol 2001;27:558-63.

3. Kalmár K, Cseke L, Horváth ÖP. Aboral pouch construction after total gastrectomy with or without preservation of the duodenal passage - a prospective, randomized study. In: Brennan MF, editor. Publication of the Proceedings of the 4th International Gastric Cancer Congress. New York: Monduzzi Editore; 2001. p. 229-35.

4. Kalmár K, Németh J, Ember Á, Pótó L, Kelemen D, Horváth ÖP. Postprandial gastrointestinal hormone production is different, depending on the type of reconstruction following total gastrectomy. Ann Surg 2006;243:465-71.

5. Horváth ÖP, Kalmár K, Cseke L. Aboral pouch with preserved duodenal passage - new reconstruction method after total gastrectomy. Dig Surg 2002;19:261-4.

6. Onodera T. Prognostic nutritional index in gastrointestinal surgery of malnourished cancer patients. Jpn J Surg 1984;85: 1001-5.

7. Pellegrini CA, Deveney CW, Patti MG, Lewin M, Way LW. Intestinal transit of food after total gastrectomy and Roux-Y esophagojejunostomy. Am J Surg 1986;151:117-24.

8. Eypasch E, Williams JI, Wood-Dauphinée S, Ure BM, Schmülling C, Neugebauer E, et al. Gastrointestinal Quality of Life Index: development, validation and application of a new instrument. Br J Surg 1995;82:216-22.

9. Troidl H, Kusche J, Vestweber KH, Eypash E, Maul U. Pouch versus esophagojejunostomy after total gastrectomy: a randomized clinical trial. World J Surg 1987;11:699-712.

10. Schmitz R, Moser KH, Treckmann J. Lebensqualität nach prograder Jejunuminterposition mit und ohne Pouch. Eine prospective Studie bei Magenkarzinompazienten zur Frage des Reservoirs als Rekonstruktionsprinzip nach totaler Gastrektomie. Chirurg 1994;64:326-32.

11. Nakane Y, Okumura S, Akehira K, Okamura S, Boku T, Okusa $\mathrm{T}$, et al. Jejunal pouch reconstruction after total gastrectomy for cancer. A randomized controlled trial. Ann Surg 1995;222: $27-35$. 
12. Liedman B, Andersson H, Berglund B, Bosaeus I, Hugosson I, Olbe L, et al. Food intake after gastrectomy for gastric carcinoma: the role of a gastric reservoir. Br J Surg 1996;83:1138-43.

13. Bozetti F, Bonfanti G, Castellani R, Maffioli L, Rubino A, Diazzi G, et al. Comparing reconstruction with Roux-en-Y to a pouch following total gastrectomy. J Am Coll Surg 1996;183: 243-8.

14. Schwarz A, Büchler M, Usinger K, Rieger H, Glasbrenner B, Friss $\mathrm{H}$, et al. Importance of the duodenal passage and pouch volume after total gastrectomy and reconstruction with the Ulm pouch: prospective randomized clinical study. World J Surg 1996;20:60-6.

15. Tanaka T, Fujiwara Y, Nakagawa K, Kusunoki M, Utunomiya J. Reflux esophagitis after total gastrectomy with jejunal pouch reconstruction: comparison of long and short pouches. Am J Gastroenterol 1997;92:821-4.

16. Iivonen MK, Koskinen MO, Ikonen TJ, Matikainen MJ. Emptying of the jejunal pouch and Roux-en-Y limb after total gastrectomy: prospective randomised study. Eur J Surg 1999;165:7427.

17. Büchin P, Fass J, Dreuw B, Schumpelik V. Prospektiv randomizierte Studie zur function des Jejunum-pouch als Ersatzmagen nach Gastrektomie. Kongressbd Dtsch Ges Chir Kongr 1999; 116:1264-7.

18. Hoksch B, Ablassmaier B, Zieren J, Müller JM. Quality of life after gastrectomy: Longmire's reconstruction alone compared with additional pouch reconstruction. World J Surg 2002;26: 335-41.

19. Gioffre'Florio MA, Bartolotta M, Miceli JC, Giacobbe G, Saitta FP, Paparo MT, et al. Simple versus double jejunal pouch for reconstruction after total gastrectomy. Am J Surg 2000;180: 24-8.

20. Fujiwara Y, Kusunoki M, Nakagawa K, Tanaka T, Hatada T, Yamamura T. Evaluation of J-pouch reconstruction after total gastrectomy: $\rho$-double tract versus J-pouch double tract. Dig Surg 2000;17:475-82.

21. Kono K, Iizuka H, Sekikawa T, Sugai H, Takahashi A, Fujii H, et al. Improved quality of life with jejunal pouch reconstruction after total gastrectomy. Am J Surg 2003;185:150-4.

22. Mochiki E, Kamiyama Y, Aihara R, Nakabayashi T, Kamimura $\mathrm{H}$, Asao T, et al. Postoperative functional evaluation of jejunal interposition with or without a pouch after a total gastrectomy for gastric cancer. Am J Surg 2004;187:728-35.

23. Basso N, Materia A, Gizzonio D, Marcelli M, De Marco M, Tamburrano G. Nutritional effects of total gastrectomy. A prospective randomised study of Roux-en-Y versus LongmireMouchet reconstruction. Ital J Surg Sci 1985;15:335-40.

24. Raab M, van Maercke P, Stützer H. Lebensqualitat nach gastrectomie-vergleich der Magenersatzmethoden nach Longmire und Roux. Zentralbl Chir 1987;112:1140-5.

25. Fuchs KH, Thiede A, Engemann R, Deltz E, Stremme O, Hamelmann $\mathrm{H}$. Reconstruction of the food passage after total gastrectomy: randomized trial. World J Surg 1995;19:698-705.

26. Nakane Y, Michiura T, Inoue K, Okumura S, Yamamichi K, Hioki K. A randomised clinical trial of pouch reconstruction after total gastrectomy for gastric cancer: which is the better technique, Roux-en-Y or interposition? Hepatogastroenterology 2001;48: 903-7.

27. Schwarz A, Beger HG. Gastric substitute after total gastrectomyclinical relevance for reconstruction techniques. Langenbeck's Arch Surg 1998;383:485-91.

28. Lehnert T, Buhl K. Techniques of reconstruction after total gastrectomy for cancer. Br J Surg 2004;91:528-39.

29. Hunt CJ. Construction of food pouch from segment of jejunum as substitute for stomach in total gastrectomy. Arch Surg 1952; 64:601-8.

30. Rodino R. Contribution á la technique de l' anastomose oesophagojéjunale aprés gastrectomie total. J Chir 1952;68:716-29.

31. Lawrence W Jr. Reservoir construction after total gastrectomy: an instructive case. Ann Surg 1962;155:191-8.

32. Kalmár K, Cseke L, ZámbóK, Horváth ÖP. Comparing aboral pouch construction with simple Roux-en-Y reconstruction after total gastrectomy (in Hungarian). Orv Hetil 2000;141:393-7.

33. Paulino F. Total gastrectomy. Acquired experience in 85 operations with special reference to the construction of a jejumal bag as a stomach substitute (in Portuguese). Hospital Rio J 1967;72:1-13.

34. Nadrowski L. Is a distal jejuno-jejunal pouch nutritionally ideal in total gastrectomy? Am J Surg 2003;185:349-53.

35. Siewert JR, Peiper HJ. Die Oesophago-jejunoplicatio. Eine Anastomosentechnik zur Refluxverhütung nach totaler Gastrektomie. Chirurg 1973;44:115-20. 